\title{
A hydro-sedimentary modeling system for flash flood propagation and hazard estimation under different agricultural practices
}

\author{
N. N. Kourgialas and G. P. Karatzas \\ Department of Environmental Engineering, Technical University of Crete, Polytechnioupolis, 73100 Chania, Greece \\ Correspondence to: N. N. Kourgialas (nektarios.kourgialas@enveng.tuc.gr) and G. P. Karatzas (karatzas@mred.tuc.gr) \\ Received: 2 September 2013 - Published in Nat. Hazards Earth Syst. Sci. Discuss.: 23 October 2013 \\ Revised: 23 September 2013 - Accepted: 9 February 2014 - Published: 18 March 2014
}

\begin{abstract}
A modeling system for the estimation of flash flood flow velocity and sediment transport is developed in this study. The system comprises three components: (a) a modeling framework based on the hydrological model HSPF, (b) the hydrodynamic module of the hydraulic model MIKE 11 (quasi-2-D), and (c) the advection-dispersion module of MIKE 11 as a sediment transport model. An important parameter in hydraulic modeling is the Manning's coefficient, an indicator of the channel resistance which is directly dependent on riparian vegetation changes. Riparian vegetation's effect on flood propagation parameters such as water depth (inundation), discharge, flow velocity, and sediment transport load is investigated in this study. Based on the obtained results, when the weed-cutting percentage is increased, the flood wave depth decreases while flow discharge, velocity and sediment transport load increase. The proposed modeling system is used to evaluate and illustrate the flood hazard for different riparian vegetation cutting scenarios. For the estimation of flood hazard, a combination of the flood propagation characteristics of water depth, flow velocity and sediment load was used. Next, a well-balanced selection of the most appropriate agricultural cutting practices of riparian vegetation was performed. Ultimately, the model results obtained for different agricultural cutting practice scenarios can be employed to create flood protection measures for flood-prone areas. The proposed methodology was applied to the downstream part of a small Mediterranean river basin in Crete, Greece.
\end{abstract}

\section{Introduction}

Due to climate change, the frequency and magnitude of flash flood events are expected to increase in the near future (Kleinen and Petschel-Held, 2007; de Moel et al., 2009). Moreover, the economic losses caused by flood events in Europe have been increasing dramatically during the past years, mainly due to the significant increase in population and economic activities in flood hazard zones (Plate, 2002).

For any floodplain management plan, the knowledge of hydrodynamic parameters in time and space is required. Commonly, these parameters are flood inundation, discharge and flow velocity (Patro et al., 2009; Pramanik et al., 2010). Hydrodynamic modeling can play a significant role in determining the values of these parameters. Several numerical models, using different computational algorithms, have been developed in order to solve the Saint Venant equations for river and floodplain flow simulation (Chatterjee et al., 2008). Software tools, such as the MIKE 11 hydraulic model developed at the Danish Hydraulic Institute (DHI, 1997) and the HEC-RAS (HEC River Analysis System) model from the US Army Corps of Engineers (USACE1, 2002), have been used extensively for the dynamic one-dimensional flow simulation in rivers.

A crucial factor that affects the flooding flow is the sediment transport load that can lead to the phenomenon of siltation in waterways and erosion of river banks (EtemadShahidi et al., 2010). Sediment in rivers is usually into two categories divided based on its physical properties: (i) cohesive fine sediment, with particles which can cluster together (typically wash load and suspended load), and (ii) noncohesive gravel sediment, behaving as individual particles, which can be suspended load or bedload. The non-cohesive 
sediment dominates the main channel and is responsible for the overall channel shape (e.g., width, depth, slope), while fine cohesive sediment is important for floodplain sedimentation and/or siltation of river waterways (DHI, 2011). The erosion, deposition and flocculation processes make the simulation of sediment transport a difficult task. Thus, considerable effort has been put into the modeling of hydrodynamics and cohesive sediment transport (Etemad-Shahidi et al., 2010). Numerical models of sediment transport are usually extensions of hydrodynamic models, as equations of sediment transport require current velocity components that are normally obtained by a hydrodynamic model.

It is well known that, in flood hydrodynamic simulation, flow resistance is a critical parameter in determining flow velocity, water depth and sediment load. In numerical flood simulations, flow resistance is commonly defined by Manning's coefficient $(n)$, whose high values indicate high flow resistance. Riparian vegetation, which consists of the vegetation on the land immediately adjacent to a stream, is often the dominant factor affecting channel roughness (Tabacchi et al., 2000; Gurnell et al., 2006). Channel roughness is a measure of the frictional resistance of a channel (bed/bank) to river flow.

It is important to identify to what extent the riparian vegetation affects the magnitude of a flood event. According to Anderson et al. (2006) and Tabacchi et al. (2000), the smaller floods with low- or mid-sized flood peaks (high probability of occurrence) are more sensitive to the riparian vegetation conditions than larger floods with high discharges (low probability of occurrence). Therefore, in the case of flash floods, which are high-probability events, occur suddenly, and have limited spatial extent, riparian vegetation management can control the consequences of floods. The significance of riparian vegetation on flood control depends on the length and width/depth ratio of the channel. Anderson et al. (2006) has reported that the smaller the channel, the higher the relative effect of riparian vegetation. Specifically, riparian vegetation is likely to have a significant effect on flood control for a channel width/depth ratio less than 17 (Masterman and Thorne, 1992). Thus, the role of riparian vegetation in controlling overbank flows in small channels with extensive riparian vegetation can be very important. A common agricultural practice to overcome flooding is the annual mowing of the riparian vegetation body by mechanical means. This practice restores discharge capacity but has negative ecological impact (Vereecken et al., 2006). A better approach is to use a well-balanced riparian vegetation management plan which minimizes the flood damages, while at the same time ensures the biodiversity of riparian vegetation (Leu et al., 2008).

Based on the European Floods Directive (CEC, 2007), all EU members should prepare flood hazard maps and flood risk management plans by 22 December 2015. Out of several flood parameters, flood hazard maps usually show only water depth information. However, in order to evaluate the overall flood hazard, flow parameters such as water depth and flow velocity should be aggregated into qualitative classes and combined to calculate a measure for the flood danger (de Moel et al., 2009). The development of different flood hazard maps for various flood management plans would also be useful.

The main objective of this study is to develop an integrated modeling system for the estimation of flood propagation characteristics (flow velocity and sediment transport) and flood hazard for an oncoming flood event based on the requirements of the European Floods Directive. The modeling system has a modular structure that combines several submodels: (a) a modeling framework based on hydrological model HSPF (Hydrological Simulation Program - FORTRAN), (b) the distributed MIKE 11 hydrodynamic module (quasi-2-D), and (c) the MIKE 11 suspended sediment transport module. This system is used to evaluate flood parameters such as water depth, discharge, flow velocity and sediment transport load for an oncoming flood event. In this study, the relationships between riparian vegetation and flood propagation characteristics that determine flood hazard were incorporated into the modeling system. Therefore, the system can be used to investigate the effect of different riparian vegetation cutting scenarios on flood hazard. The proposed modeling system can be used as an effective tool for the estimation of flood hazard and for the well-balanced selection of the appropriate riparian vegetation cutting management plan that will minimize the degree and extent of flood hazard.

\section{Study area}

The Koiliaris River basin is located in the eastern part of the Chania Prefecture in Crete, Greece (Fig. 1). The watershed extends from the White Mountains (highest altitude $2041 \mathrm{~m}$ a.m.s.l.) to the coastline and covers a total area of $130 \mathrm{~km}^{2}$. The Koiliaris River has four tributaries (two permanent and two temporary). Three telemetric hydrometric stations (H1, H2, H3) and two meteorological stations (M1, M2), exist in the Koiliaris River basin and provide hourly real-time data (Kourgialas and Karatzas, 2011) (Fig. 1). The study area consists of carbonate formations, flysch, Quaternary-Neogenic and alluvial deposits.

In the past, several extreme flash flood events have occurred in the downstream area of the basin (Fig. 1). The downstream part of the basin has a short length $(3.6 \mathrm{~km})$, a very small width/depth ratio (less than 3.5 ), and is characterized by dense riparian vegetation. Moreover, the topography of the downstream study area of the Koiliaris River basin is smooth, with a low topographic slope of $6 \%$. Taking into consideration the above channel characteristics, it is concluded that appropriate riparian vegetation management can assist in flash flood prevention and control plans. In order to investigate the role of riparian vegetation on flash flood propagation characteristics, the high flash flood event of 7 December 2000 that took place in the downstream area of the Koiliaris River was considered. 

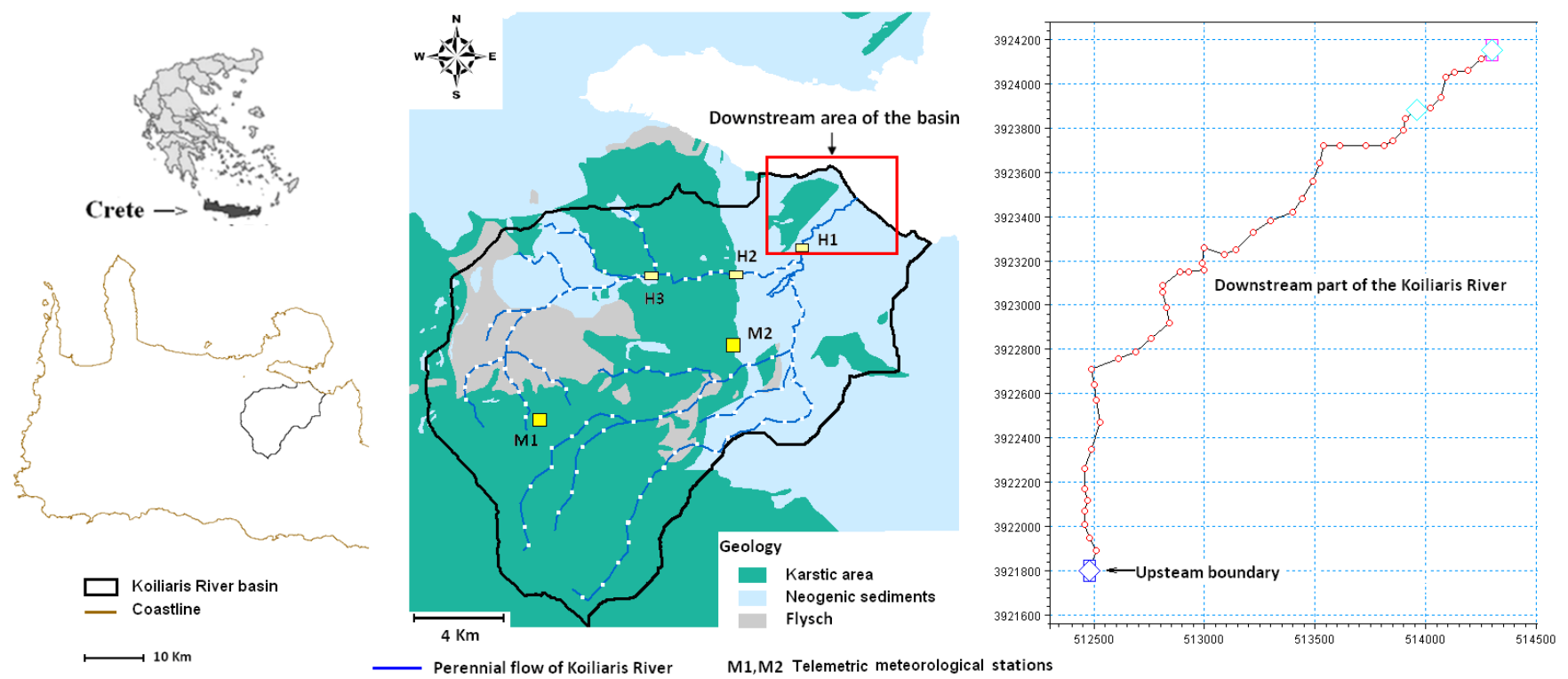

Perennial flow of Koiliaris River M1,M2 Telemetric meteorological station

Fig. 1. Geology of the Koiliaris River basin and location of the upstream boundary of the model area.

\section{Methodology}

\subsection{The concept of the modeling system}

The developed modeling framework is an integrated hydrosedimentary model with a modular design which connects three submodels. The first one is a framework based on the hydrological model HSPF. The time series output from HSPF becomes input for the second submodel, the hydrodynamic module of MIKE 11 (quasi-2-D), in order to simulate flood inundation at a specific river reach. The hydrodynamic module output is used as input for the third submodel, the advection-dispersion (AD) module of MIKE 11 which has the capability of estimating the suspended sediment load during a flash flood event. The first and second submodels have already been successfully calibrated and validated for the study area in previous work by the authors (Kourgialas et al., 2010; Kourgialas and Karatzas, 2013). The impact of riparian vegetation on water depth and discharge was studied in Kourgialas and Karatzas (2013). The contribution of the present work, as a continuation of the previous one, is to investigate the role of riparian vegetation on flow velocity and sediment transport. The changes in flow velocity for different agricultural practices were simulated in 1-D and 2-D using the second submodel, and the sediment load simulation was performed using the advectiondispersion submodel. Utilizing this integrated modeling approach, two-dimensional flood hazard maps were generated for different weed-cutting practices. Such maps can be used by decision-makers to objectively compare different management scenarios that can affect the degree and extent of flood hazard in flood-prone areas. A graphical representation of the

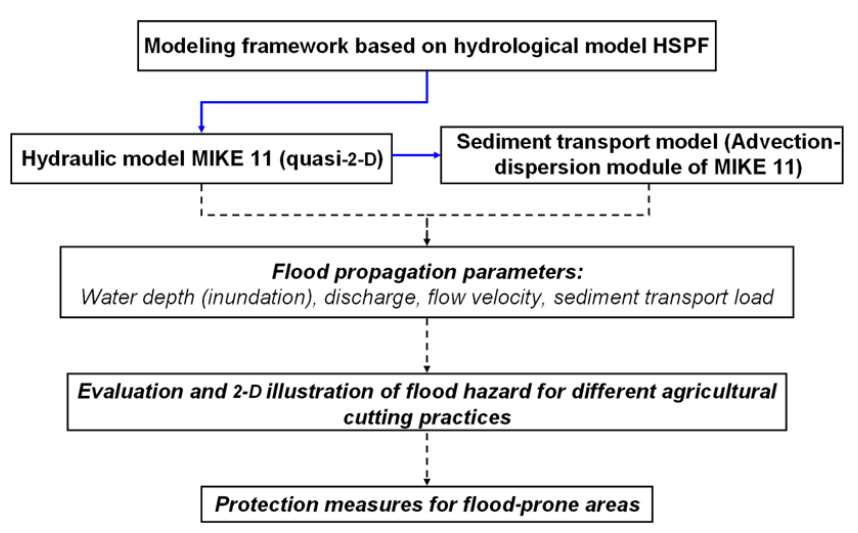

Fig. 2. Flow chart of the proposed hydro-sedimentary modeling system.

integrated hydro-sedimentary modeling system is presented in Fig. 2.

\subsection{A framework based on HSPF}

The modeling framework is based on Hydrological Simulation Program - FORTRAN (HSPF) and also includes a karstic model for estimating spring discharge, an Energy Budget Snow Melt model and an empirical karstic channel model. This framework is capable of simulating the surfaceand groundwater flow that generates flash flood events in the downstream area of any complex hydrogeological basin. 


\subsection{The hydrodynamic module of MIKE 11}

The hydrodynamic module of MIKE 11 uses an implicit finite difference model for unsteady channel flow simulation and quasi two-dimensional model for floodplain flow simulation. It solves the full dynamic and width-integrated equations of continuity and conservation of momentum (Saint Venant equations). A six-point implicit staggered grid finite difference scheme developed by Abbott and Ionescu (1967) is used for solving the Saint Venant equations. This submodel was calibrated based on the flash flood event of 10 December 2003, and validated for the flash flood event of 7 December 2000 in previous work (Kourgialas and Karatzas, 2013). The high flash flood event that took place on 7 December 2000 is used in this work to investigate the impact of different weed-cutting scenarios on flash flood flow velocity and sediment transport.

Input data to the hydrodynamic module, such as the river network, the cross section, the boundary parameter and the hydrodynamic parameter files must be processed (DHI, 2007). The boundary parameter file includes the hourly time series boundary conditions that were defined using the time series output of the HSPF-based framework (Kourgialas et al., 2010). Manning's coefficient $(n)$ is used as the resistance coefficient in the hydrodynamic parameter file. River cross sections were divided into three riparian vegetation zones with different bed resistance values: (a) the bottom zone for the description of low to moderate flows (Riparian Zone 1), (b) the bank zone for the description of moderate to high flows (Riparian Zone 2), and (c) the overbank and floodplain flow zone (Riparian Zone 3). The effect of different riparian vegetation cutting scenarios on flood propagation was investigated based on the above classification. The grid cell size of the output 2-D flood inundation and velocity maps were defined as $1 \mathrm{~m}$, while the computational time step was set to $1 \mathrm{~min}$. The detailed description of the development of this submodel, for the flash flood event of 7 December 2000 is provided in Kourgialas and Karatzas (2013).

\subsection{The advection-dispersion (AD) module of MIKE 11}

\subsubsection{Mathematical formulation}

The advection-dispersion module of MIKE 11 for transport modeling is based on the one-dimensional equation of conservation of mass of dissolved or suspended material (e.g., fine sediments). The module requires the output from the hydrodynamic module, in other words, discharge and water level, cross-section area, and hydraulic radius. The basic equation in this module is the advection-dispersion equation:

$$
\frac{\partial \mathrm{AC}}{\partial t}+\frac{\partial Q C}{\partial x}-\frac{\partial}{\partial x}\left(\operatorname{AD}_{L} \frac{\partial C}{\partial x}\right)=-k C A+C_{2} q+E w,
$$

where $A$ is cross-section area, $C$ is the concentration, $D_{L}$ the horizontal dispersion coefficient, $k$ the linear decay coefficient, $C_{2}$ is source/sink concentration, $q$ the lateral inflow, $E$ the net deposition/erosion, $x$ the space coordinate, and $t$ the time coordinate. In our case study, $C_{2}$ is the tributary concentration, $q$ the tributary inflow per unit length and $w$ the river width.

The above equations are solved numerically using an implicit finite difference scheme. The model simulates both temporal and spatial (longitudinal) variations of sediment concentration, as well as accumulated sediment deposits over the simulation period (DHI, 2007). The AD module includes a relatively simple description of the erosion and deposition as source/sink terms in the $\mathrm{AD}$ equation. In the case of deposition, the net deposition term $E$ is given by

$E=\frac{W_{S} C}{H^{*}}\left(1-\frac{v^{2}}{v_{\mathrm{cd}}^{2}}\right) v<v_{\mathrm{cd}}($ deposition $)$,

where $v$ is the flow velocity, $v_{\mathrm{cd}}$ the critical deposition velocity, $W_{s}$ the fall velocity, and $H^{*}$ the average depth (of the section) through which the particles settle.

In the case of erosion, the net erosion term $E$ is expressed as

$E=\frac{M}{h}\left(1-\frac{v^{2}}{v_{\mathrm{ce}}^{2}}\right) v \geq v_{\mathrm{ce}}($ erosion $)$,

where $v_{\text {ce }}$ is the critical erosion velocity, $M$ the erodibility coefficient, and $h$ the flow depth.

The module was successfully tested and used by Neary et al. (2001), Parsa et al. (2007) and Etemad-Shahidi et al. (2010). Specifically, Parsa et al. (2007) showed that it can be used effectively compared to 2-D and even 3-D sediment transport models.

\subsubsection{Calibration and validation}

The input data that must be prepared for running the $\mathrm{AD}$ module are (a) the time series of suspended sediment concentration at the upstream boundary, and (b) the sediment characteristics, such as grain size, initial conditions of concentration, fall velocity, critical shear stress for deposition/erosion, erodibility coefficient and dispersion coefficient (DHI, 2007).

The AD module was calibrated and validated for the time period from 2011-2013, when a sampling campaign took place at the downstream part of the Koiliaris River. Specifically, 15 samples of suspended sediment were collected at hydrometric station $\mathrm{H} 1$ and river bank soil samples were also collected at 9 different locations along the downstream part of the river. The soil samples were used to determine the sediment characteristics experimentally. The calibration process was based on the dispersion coefficient because it plays a significant role in sediment transport. Nine of the collected suspended sediment samples were used for calibration, while the remaining six were used for the validation process. 
The calibrated and validated module was then used for the study of the high flash flood event that took place on 7 December 2000. One of the main challenges associated with this task was determining the boundary time series of suspended sediment, due to lack of measurements for this specific event. In order to overcome this lack of data, a regression equation was developed based on the suspended sediment samples collected at station H1. Since discharge and rainfall are considered the main factors controlling the production and delivery of sediment (Nadal-Romero et al., 2008; Rodriguez-Blanco et al., 2010), the regression equation is as follows:

$\mathrm{SSC}=a D+b P+c$,

where SSC is the suspended sediment concentration $\left(\mathrm{mg} \mathrm{L}^{-1}\right), D$ the discharge $\left(\mathrm{m}^{3} \mathrm{~s}^{-1}\right), P$ the accumulated rainfall (mm), and $a, b, c$ are coefficients.

The discharge measurements from station $\mathrm{H} 1$ and the rainfall data from station M1 were used in the above equation.

\subsection{Flood propagation scenarios based on weed-cutting practices - flood hazard rating maps}

The flow characteristics of the study flash flood event are estimated from the hydro-sedimentary modeling system described above. Water depth, discharge, flow velocity and sediment load were determined along the downstream part of the Koiliaris River basin. Usually, in hydraulic modeling, the parameter that corresponds to weed cutting is the Manning roughness coefficient (Leu et al., 2008). The determination of the Manning roughness coefficient, based on weed-cutting practices, is a very difficult task as it varies constantly due to the different river geomorphological characteristics and the variation in riparian vegetation cutting patterns. Thus, in cases when the relationship between the Manning roughness coefficient and the weed-cutting percentage can not be determined due to lack of field data, literature values from laboratory and field experiments from channels with similar characteristics to the river can be utilized with relatively low uncertainty. Based on this, in this study we obtain Manning roughness coefficient information from both sources mentioned above. Three different weed-cutting scenarios were considered in order to investigate the role of riparian vegetation on flood propagation modeling in an integrated way for the flood event under study (Doncker et al., 2009; Kourgialas and Karatzas, 2013):

a. no cutting scenario (using the calibrated Manning coefficient),

b. $40 \%$ weed cutting corresponding to a $27 \%$ reduction in Manning's coefficient, and

c. $57 \%$ weed cutting corresponding to a $62 \%$ reduction in Manning's coefficient.
In addition, in order to have more robust results, a sensitivity analysis of the reduction in Manning's coefficient due to weed-cutting scenarios was performed. For this purpose, reasonable perturbation percentages were applied to scenarios $\mathrm{B}$ and $\mathrm{C}$ and the change in velocity and sediment transport results was computed after each change. The values of the reduction in Manning's coefficient were perturbed by $\pm 5 \%$.

From the results of the authors' prior work (Kourgialas and Karatzas, 2013), the effect of weed-cutting on the flood wave characteristics is minor in Riparian Zones 1 and 2, while is significant in Riparian Zone 3. For this reason, weed cutting only in Riparian Zone 3 was investigated in this study. The developed modeling system allows for the demonstration of the changes in the flow characteristics due to the different weed-cutting scenarios. These characteristics were simulated one-dimensionally for discharge and sediment load and twodimensionally for water depth and flow velocity. The water depth and flow velocity results for the different weed-cutting scenarios were used to determine a measure of the flood danger for each scenario. The UK flood hazard rating (van Alphen and Passchier, 2007; de Moel et al., 2009) was used as a measure of the flood danger. It is defined as

$\mathrm{FHR}=W(V+0.5)+\mathrm{DF}$,

where FHR is the flood hazard rating, $W$ the water depth (m), $V$ the flow velocity $\left(\mathrm{m} \mathrm{s}^{-1}\right)$, and $\mathrm{DF}$ the debris factor. The debris factor is equal to 1 for $W>0.25$ and equal to 0.5 otherwise.

Using the above flood hazard rating and taking into consideration the sediment load results, the well-balanced weedcutting scenario was selected.

\section{Results and discussion}

\subsection{The hydrodynamic and sediment transport modules of MIKE 11 based on weed-cutting practices}

The hydrodynamic MIKE 11 module was successfully calibrated and validated in authors' prior work for the simulation of the flood inundation of the historical flash flood event that took place on 7 December 2000 in the study downstream river part. Manning's coefficient $(n)$ was selected as a model calibration parameter (Pramanik, 2010) at different locations (riverbed and banks) along the downstream river reach. For the area of study, the calibrated Manning coefficient takes values equal to 0.035 in Riparian Zone 1, 0.04 in the Riparian Zone 2, and between 0.04 and 0.05 in Riparian Zone 3 (floodplains).

Riparian vegetation affects flood propagation characteristics and its cutting is part of the water management strategy. Nevertheless, the riparian vegetation has an essential role in water quality control which contributes to maintenance of a sustainable ecosystem along the river and also controls erosion and sediment transport (Vereecken et al., 2006; Doncker 

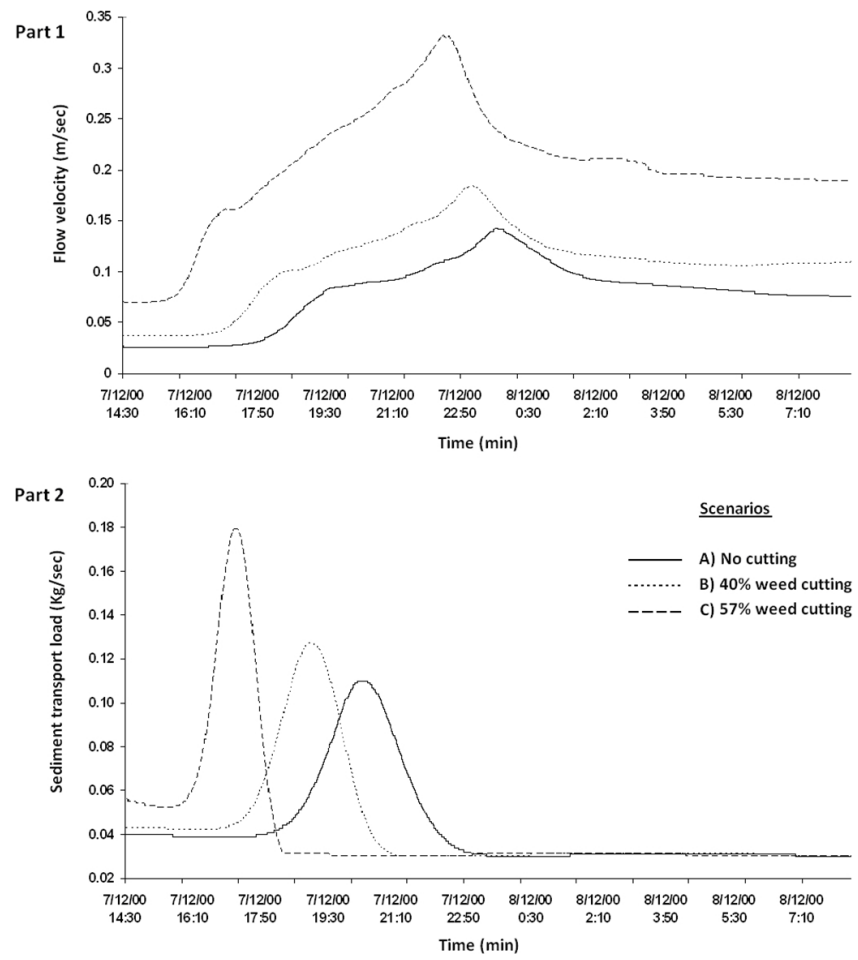

Fig. 3. Flow velocity and sediment transport load for different weedcutting scenarios.

et al., 2009). Kourgialas and Karatzas (2013) investigated the effect of weed-cutting scenarios A, B and C on water depth and discharge. The aim of this work is to study the impact of the same weed-cutting scenarios on velocity and sediment transport. The results of the previous study show that the higher the weed-cutting percentage, the lower the flood wave depth and the higher the flow discharge. For instance, $40 \%$ weed cutting (scenario B) reduces the flood wave peak from 4 to $3.6 \mathrm{~m}$, while $57 \%$ weed cutting (scenario C) reduces it from 4 to $3.4 \mathrm{~m}$.

The simulation results for flow velocity at a cross section located $2100 \mathrm{~m}$ from the study area's upstream boundary (Fig. 1) are shown in Part 1 of Fig. 3 for the three cutting scenarios. As observed from the figure, the higher the weed-cutting percentage, the higher the velocity. The maximum velocity is $0.14 \mathrm{~m} \mathrm{~s}^{-1}$ for scenario $\mathrm{A}, 0.18 \mathrm{~m} \mathrm{~s}^{-1}$ for scenario $\mathrm{B}$, and $0.33 \mathrm{~m} \mathrm{~s}^{-1}$ for scenario $\mathrm{C}$. The above values correspond to a $22.2 \%$ and $57.6 \%$ increase in flow velocity peak for scenarios B and C, respectively, compared to the no cutting scenario A. Another important observation is that the flow velocity peak appears earlier in time as the weed-cutting percentage increases. It should be noted here that similar behavior was observed for the rest of the river cross sections.

A boundary condition time series of suspended sediment concentration had to be created for the advection-dispersion module. This was accomplished by using a regression equation based on the recent suspended sediment concentration
Table 1. Experimental results from river bank soil samples collected at different locations along the downstream part of the Koiliaris River (Lilli, 2011).

\begin{tabular}{lrrr}
\hline $\begin{array}{l}\text { Soil river } \\
\text { bank } \\
\text { sample }\end{array}$ & $\begin{array}{r}\text { Channel distance } \\
\text { from upstream } \\
\text { boundary }(\mathrm{m})\end{array}$ & $\begin{array}{r}\text { Critical shear } \\
\text { stress } \\
(\mathrm{Pa})\end{array}$ & $\begin{array}{r}\text { Erodibility } \\
\text { coefficient }) \\
\left(\mathrm{cm}^{3} / \mathrm{Ns}\right)\end{array}$ \\
\hline 1 & 325.2 & 0.11 & 0.302 \\
2 & 363.5 & 0.15 & 0.258 \\
3 & 377.2 & 0.14 & 0.267 \\
4 & 560.2 & 0.35 & 0.169 \\
5 & 573.2 & 0.25 & 0.200 \\
6 & 726.6 & 0.21 & 0.218 \\
7 & 841.6 & 0.18 & 0.236 \\
8 & 960.2 & 0.21 & 0.218 \\
9 & 1065.2 & 0.18 & 0.236 \\
\hline
\end{tabular}

measurements, on the discharge measurements, and the rainfall data as follows:

$\mathrm{SSC}=0.064 D+0.06 P+2.112, \quad R^{2}=0.85$,

where SSC is the suspended sediment concentration (mg L $\left.{ }^{-1}\right), D$ the discharge $\left(\mathrm{m}^{3} \mathrm{~s}^{-1}\right)$, and $P$ the accumulated rainfall $(\mathrm{mm})$.

The sediment transport model calibration was performed using the dispersion coefficient as calibration parameter, as the rest of the input data were available from experimental results (Table 1). For comparison purposes, Table 2 summarizes the available sediment transport load data along with the corresponding simulation results. The determination index $\left(R^{2}\right)$ was also calculated in order to demonstrate the goodness of fit of the calibrated $\left(R^{2}=0.93\right)$ and validated $\left(R^{2}=0.86\right)$ models. Despite the fact that measurement data are limited, a very good fit was achieved for both processes using a dispersion coefficient equal to $0.32 \mathrm{~m}^{2} \mathrm{~s}^{-1}$.

The simulation results for the sediment transport load obtained by using the above regression equation as boundary condition to the calibrated model are shown in Fig. 3 (Part 2). The results were generated for the same cross section that was used for the velocity results. As observed in the figure, the higher the weed-cutting percentage, the higher the sediment transport load. The maximum sediment transport load is $0.110 \mathrm{~kg} \mathrm{~s}^{-1}$ for scenario A, $0.127 \mathrm{~kg} \mathrm{~s}^{-1}$ for scenario $\mathrm{B}$, and $0.179 \mathrm{~kg} \mathrm{~s}^{-1}$ for scenario $\mathrm{C}$. These values correspond to a $13.4 \%$ and $38.5 \%$ increase in the sediment transport peak for scenarios B and C, respectively, compared to the no cutting scenario A. Similar to the behavior observed in the velocity results, the sediment transport peak appears earlier in time as the weed-cutting percentage increases. Furthermore, as the cutting percentage increases, changes in the sediment transport load as a function of time are steeper. The same trends were verified for all river cross sections examined. 

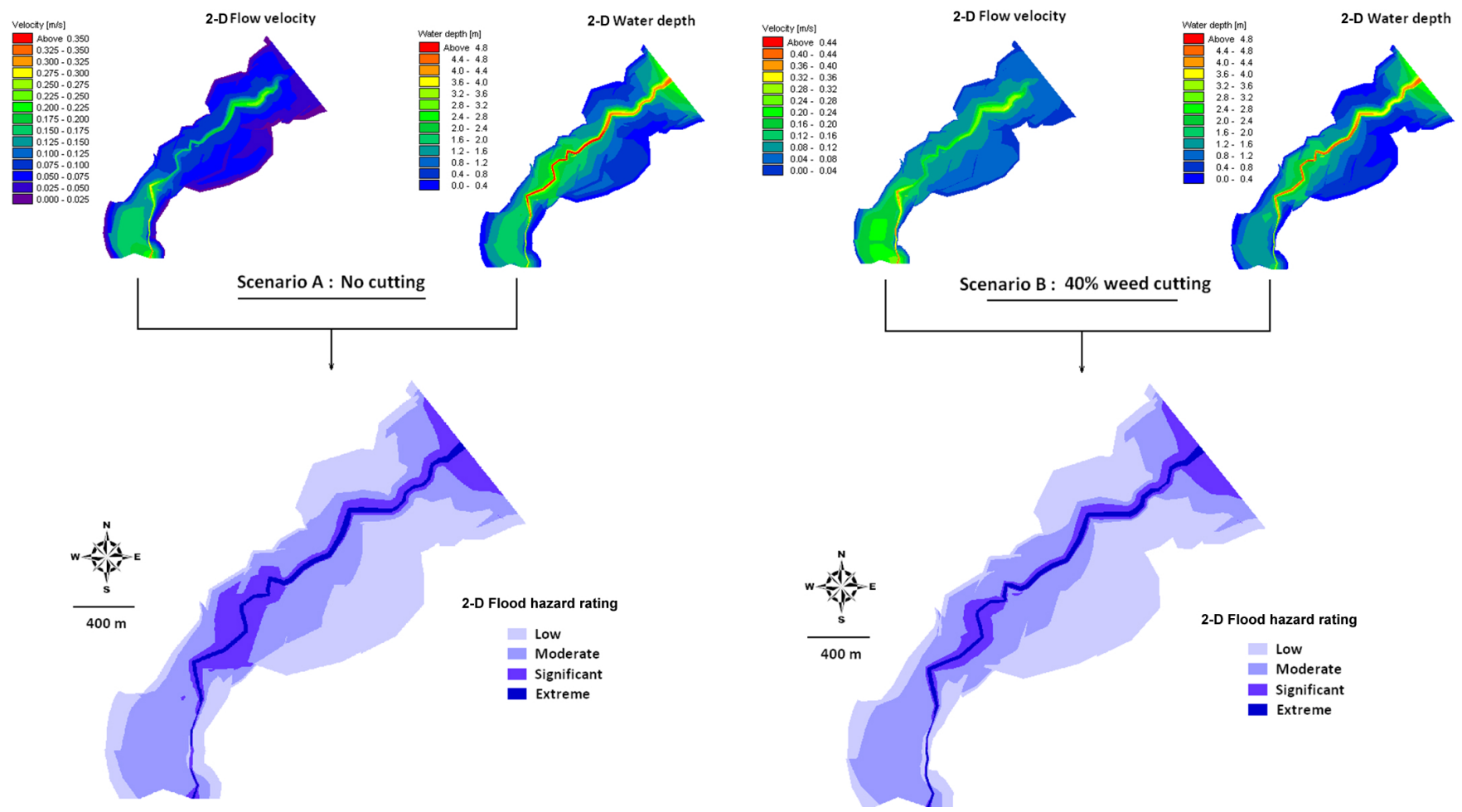

Fig. 4. Flow velocity, flood inundation and flood hazard rating maps for scenario A (no weed cutting).

\subsection{Sensitivity analysis}

A sensitivity analysis of Manning's coefficient was performed for weed-cutting scenarios B and C for the cross section located $2100 \mathrm{~m}$ from the study area's upstream boundary. Based on the values of Manning's coefficient that were perturbed by $\pm 5 \%$, four cases were considered in order to investigate the change in velocity and sediment transport results.

$\mathrm{B}+$ ) $40 \%$ weed cutting corresponding to a $32 \%$ reduction in Manning's coefficient,

B-) $40 \%$ weed cutting corresponding to a $22 \%$ reduction in Manning's coefficient,

$\mathrm{C}+$ ) $57 \%$ weed cutting corresponding to a $67 \%$ reduction in Manning's coefficient, and

$\mathrm{C}-$ ) $57 \%$ weed cutting corresponding to a $57 \%$ reduction in Manning's coefficient.

Based on the sensitivity analysis results, the maximum velocity is $0.20 \mathrm{~m} \mathrm{~s}^{-1}$ for case $\mathrm{B}+, 0.17 \mathrm{~m} \mathrm{~s}^{-1}$ for case $\mathrm{B}-$, $0.37 \mathrm{~m} \mathrm{~s}^{-1}$ for case $\mathrm{C}+$, and 0.31 for case $\mathrm{C}-$. The above values correspond to a $10.4 \%$ and $-5.4 \%$ change in the flow velocity peak for cases $\mathrm{B}+$ and $\mathrm{B}-$, respectively, compared to scenario $\mathrm{B}$. For cases $\mathrm{C}+$ and $\mathrm{C}-$, the corresponding changes are $10.8 \%$ and $-6.5 \%$, compared to scenario $\mathrm{C}$.

In addition, the sensitivity simulation results show that the maximum sediment transport load is $0.131 \mathrm{~kg} \mathrm{~s}^{-1}$ for case $\mathrm{B}+, 0.121 \mathrm{~kg} \mathrm{~s}^{-1}$ for case $\mathrm{B}-, 0.182 \mathrm{~kg} \mathrm{~s}^{-1}$ for case $\mathrm{C}+$, and

Fig. 5. Flow velocity, flood inundation and flood hazard rating maps for scenario B ( $40 \%$ weed cutting).

$0.161 \mathrm{~kg} \mathrm{~s}^{-1}$ for case $\mathrm{C}-$. These values correspond to a $3.1 \%$ and $-4.6 \%$ change in sediment transport load for cases $\mathrm{B}+$ and $\mathrm{B}-$, respectively, compared to scenario $\mathrm{B}$ and $1.6 \%$ and $-11.2 \%$ change for cases $\mathrm{C}+$ and $\mathrm{C}-$, compared to scenario C.

\subsection{Flood hazard maps}

The hydrodynamic module of MIKE 11 has the capability of producing two-dimensional maps of the maximum flood inundation and flow velocity in the river and floodplain. Such maps were generated for each of the three weed-cutting scenarios and were combined according to Eq. (5) in order to derive the hazard rating map for each case. Figures 4-6 present the water depth, flow velocity, and the hazard rating map for scenarios A, B and C, respectively. As can be seen in the hazard rating maps, the flood hazard ratings were divided into four classes of different degree (low, moderate, significant and extreme) (Defra/Environment Agency, 2006).

The flooded area for each flood hazard class is presented in Table 3 for the three scenarios. As shown, the total flooded area was reduced by $5.95 \%$ for scenario B and by $23.9 \%$ for scenario C, compared to scenario A. More analytically, the area of the low hazard class increases slightly for scenarios $\mathrm{B}$ and $\mathrm{C}$. This is viewed as a positive effect of weed cutting since low hazard zones correspond to flood zones with shallow flowing water or deep standing water. The moderate 


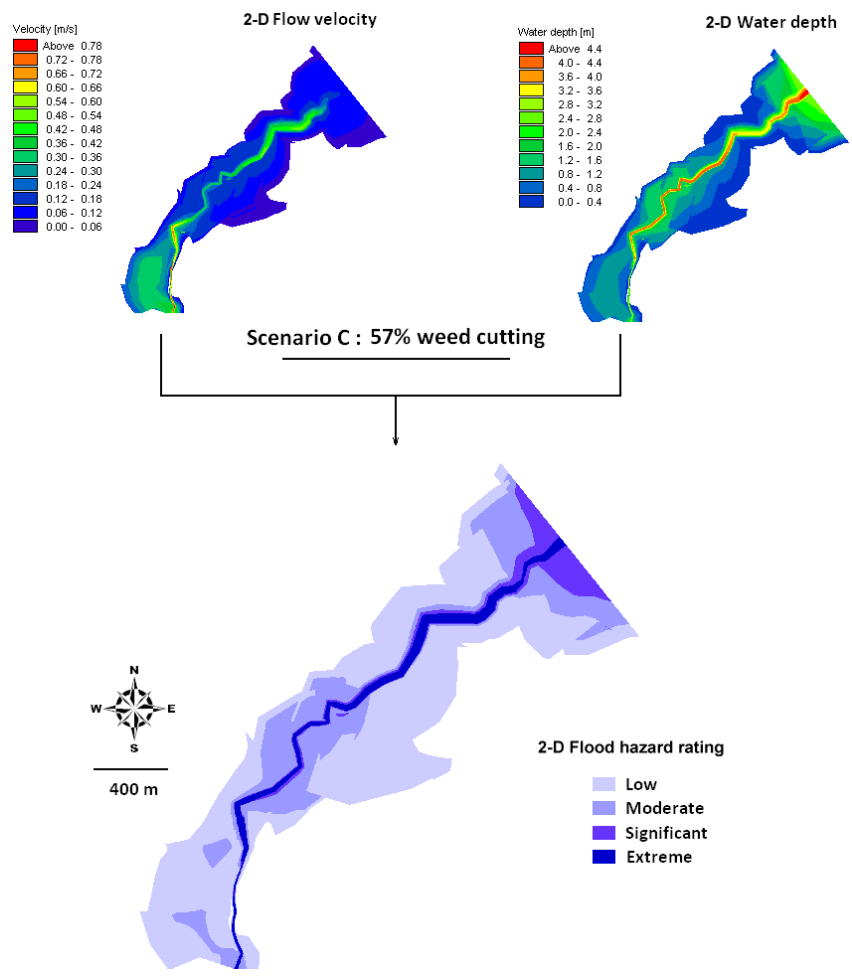

Fig. 6. Flow velocity, flood inundation and flood hazard rating maps for scenario C (57\% weed cutting).

and significant hazard zones decrease significantly when the weed-cutting percentage is increased. For the moderate hazard zone the observed increase is $7.7 \%$ for scenario B and $54 \%$ for scenario $\mathrm{C}$, while for the significant hazard zone the respective percentages are $32.4 \%$ for scenario $\mathrm{B}$ and $62.1 \%$ for scenario C. An interesting behavior is observed in the case of the extreme hazard zones, which increase when weed cutting is increased. The increase of the hazard level for the areas close to the dominant channel is a negative effect of weed cutting. This is more pronounced in the areas where the channel line meanders, as opposed to the areas where it is closer to a straight channel.

The simulation results demonstrate the necessity for an optimal riparian vegetation cutting plan which takes into account the fact that flood water depth and flow velocity are affected differently by the weed-cutting agricultural practices. Recall that the simulation results for the sediment transport load indicate that increased weed cutting results in heavier transport load. Given that heavy sediment load leads to more pronounced riverbank erosion and has a negative impact on riparian ecology, scenario B seems to be preferable, as it provides the best balance among the flood characteristics (water level, discharge, velocity, flooded area, and sediment load) in regards to their intensity. Moreover, scenario B reduces the creation of dangerous sediment transport load from an ecological and human health point of view. Through scientific studies it has been proven that the negative impact on human health and riparian ecology increases as turbidity levels rise
Table 2. Comparison of the AD submodel output and field measurements of the suspended sediment transport load for the calibration and validation processes.

\begin{tabular}{|c|c|c|c|c|}
\hline \multirow[t]{2}{*}{ Time } & \multicolumn{3}{|c|}{$\begin{array}{l}\text { Suspended sediment transport } \\
\qquad \operatorname{load}\left(\mathrm{kg} \mathrm{s}^{-1}\right)\end{array}$} & \multirow[t]{2}{*}{$R^{2}$} \\
\hline & Measured & Simulated & & \\
\hline \multicolumn{5}{|l|}{ Calibration } \\
\hline $13 / 12 / 2011$ & 0.039 & 0.020 & \multirow{9}{*}{0.93} & \\
\hline $17 / 2 / 2012$ & 0.081 & 0.090 & & \\
\hline $29 / 3 / 2012$ & 0.050 & 0.040 & & \\
\hline $25 / 6 / 2012$ & 0.013 & 0.010 & & \\
\hline 21/8/2012 & 0.001 & 0.005 & & \\
\hline $30 / 10 / 2012$ & 0.003 & 0.007 & & \\
\hline $15 / 11 / 2012$ & 0.002 & 0.010 & & \\
\hline $10 / 12 / 2012$ & 0.103 & 0.120 & & \\
\hline $14 / 12 / 2012$ & 0.106 & 0.150 & & \\
\hline \multicolumn{5}{|l|}{ Validation } \\
\hline $28 / 1 / 2013$ & 0.045 & 0.030 & \multirow{6}{*}{0.86} & \\
\hline $15 / 2 / 2013$ & 0.049 & 0.050 & & \\
\hline $11 / 3 / 2013$ & 0.047 & 0.030 & & \\
\hline $16 / 3 / 2013$ & 0.080 & 0.090 & & \\
\hline $29 / 3 / 2013$ & 0.051 & 0.030 & & \\
\hline $4 / 5 / 2013$ & 0.011 & 0.004 & & \\
\hline
\end{tabular}

(WHO, 1996). The acceptable range of turbidity depends on the size and local conditions of a studied river. Nevertheless, a general guide for small rivers, such as the Koiliaris River, is that turbidity above 5 NTU can have negative ecological or human health effects (WHO, 1996; EPA, 2007). In this study, based on water sampling and turbidity measurements at the downstream part of the Koiliaris River, a regression function was determined between total suspended solids and turbidity. Specifically, it was found that the concentration of total suspended solids $\left(\mathrm{mg} \mathrm{L}^{-1}\right)$ is equal to 0.504 of the turbidity value (NTU) $\left(R^{2}=0.97\right)$. Based on this function, the turbidity for scenario A was estimated to reach $2.8 \mathrm{NTU}$, for scenario B 3.4 NTU, and for scenario C 5.1 NTU. Taking into consideration the limit of 5 NTU, scenario B can be characterized as safe for ecological and human health.

\subsection{Advantages and limitations of the proposed modeling system}

One of the main advantages of the proposed modeling system is the short computation time. Specifically, MIKE 11 (quasi2-D) combines a simplified two-dimensional representation of the flood inundation characteristics with a fast computation process. Moreover, many studies indicate that despite the fact that, compared to two-dimensional models, MIKE 11 quasi-2-D fails to provide detailed information regarding the flow field, it has generally similar accuracy in the estimation of the flood inundation area, especially for flood flows 
Table 3. Flooded area for different flood propagation scenarios and different flood hazard degrees.

\begin{tabular}{llccc}
\hline $\begin{array}{l}\text { Thresholds for } \\
\begin{array}{l}\text { Flood Hazard } \\
\text { Rating (FHR)* }\end{array}\end{array}$ & $\begin{array}{l}\text { Degree of } \\
\text { flood hazard }\end{array}$ & \multicolumn{3}{c}{$\begin{array}{c}\text { Flooded area } \\
\left(\mathrm{km}^{2}\right)\end{array}$} \\
& & & & \\
\cline { 3 - 5 } & & scenario A & scenario B & scenario C \\
\hline$<0.75$ & Low & 1.105 & 1.161 & 1.240 \\
$0.75-1.25$ & Moderate & 1.051 & 0.970 & 0.492 \\
$1.25-2.5$ & Significant & 0.374 & 0.259 & 0.140 \\
$>2.5$ & Extreme & 0.087 & 0.090 & 0.117 \\
Total flooded area & & 2.617 & 2.480 & 1.989 \\
\hline
\end{tabular}

* Defra/Environment Agency (2006).

up to $325 \mathrm{~m}^{3} \mathrm{~s}^{-1}$ (Tuteja, 2008). The hydrodynamic code of MIKE 11 does not consider the dynamic water exchanges between the river network and the floodplain. Specifically, hydrological processes such as evapotranspiration losses or interactions between the river water and groundwater are ignored. These processes can play a very important role in flood inundation simulation of long river reaches. Thus, the proposed hydrodynamic module is particularly suitable for flash flood events, which have short duration, and relatively short river reaches of less than $5 \mathrm{~km}$ (DHI, 2007; Kourgialas and Karatzas, 2013). The AD module of MIKE 11 can simulate wash- and suspended load but not bed load particles such as rolls or jumps along the riverbed, thus the third submodel is not appropriate for simulating significant longterm morphological changes in a river reach. In the case of the present study, no significant morphological changes have been marked in the downstream part of the Koiliaris River during the last $50 \mathrm{yr}$, and the $\mathrm{AD}$ module is applicable to the case.

\section{Conclusions}

This study highlights the significant impact of riparian vegetation on flood propagation modeling, focusing on the development of a modeling system for the quick estimation of flood propagation characteristics such as the water depth, discharge, flow velocity and sediment load at river reach scale. The modeling system output is very useful, since it quickly provides substantial information that can be used in the decision-making process. Three different weed-cutting scenarios were considered in order to investigate the role of riparian vegetation on flood propagation modeling. Based on the derived simulation results an appropriate weed-cutting scenario can be planned for the riparian vegetation in order to minimize flood impact and guarantee ecological quality. Moreover, it is concluded that when the weed-cutting percentage is increased, the flood wave depth decreases while flow discharge, velocity and sediment transport load increase. The proposed modeling system can incorporate the flood propagation characteristics such as water depth, flow velocity and sediment transport load in order to estimate flood hazard as a measure of the flood danger from an oncoming flash flood event. Using the above approach, various mitigation scenarios based on the European Floods Directive can be evaluated. The benefit of this study is the creation of a modeling tool, capable of illustrating the flood inundation of an oncoming event in short time, evaluating the flood hazard based on water depth, flow velocity and sediment load, and selecting a well-balanced agricultural cutting practice with respect to the level of flood hazard.

Edited by: A. Loukas

Reviewed by: J. Kriauciuniene, I. Ribarova, and R. Romanowicz

\section{References}

Abbott, M. B. and Ionescu, F.: On the numerical computation of nearly horizontal flows, J. Hydraul., Res., 5, 97-117, 1967.

Anderson, B. G., Rutherfurd, I. D., and Western, A. W.: An analysis of the influence of riparian vegetation on the propagation of flood waves, Environ. Model. Softw., 21, 1290-1296, 2006.

CEC (Commission of European Communities): Directive 2007/60/WE of the European Parliament and of the Council 23 October 2007 on the Assessment and Management of Flood Risk, Brussels: Official Journal of the European Communities 6.11.2007 L 288, 2007.

Chatterjee, C., Förster, S., and Bronstert, A.: Comparison of hydrodynamic models of different complexities to model floods with emergency storage areas, Hydrol. Process., 22, 4695-4709, 2008.

Defra/Environment Agency: The Flood Risks to People Methodology, Flood Risks to People Phase 2, FD2321 Technical Report 1, March 2006, available at: http://sciencesearch.defra.gov. uk/Document.aspx?Document=FD2321_3436_TRP.pdf (last access: 12 March 2013), 2006.

de Moel, H., van Alphen, J., and Aerts, J. C. J. H.: Flood maps in Europe - methods, availability and use, Nat. Hazards Earth Syst. Sci., 9, 289-301, doi:10.5194/nhess-9-289-2009, 2009.

DHI: Danish Hydraulic Institute (DHI), MIKE11 GIS reference and user manual, Horsholm, Denmark, 1997.

DHI: Danish Hydraulic Institute (DHI), MIKE 11 Environmental Hydraulics, Reference Manual, Horsholm, Denmark, 2007. 
DHI: Danish Hydraulic Institute (DHI), MIKE 11 Sediment transport, cohesive and non-cohesive sediment transport model, Short Description, Horsholm, Denmark, 2011.

Doncker, L. D., Troch, P., Verhoeven, R., Bal, K., Meire, P., and Quintelier, J.: Determination of the Manning roughness coefficient influenced by vegetation in the river Aa and Biebrza river, Environ. Fluid Mech., 9, 549-567, 2009.

EPA: Guidance Booklet No. 1, Guidance for Local Authorities on Regulation 9 and 10 of the European Communities (Drinking Water) (No. 2) Regulations 2007 (S.I. No. 278 of 2007), available at: http://www.epa.ie/downloads/pubs/water/drinking (last access: 5 December 2013), 2007.

Etemad-Shahidi, A., Shahkolahi, A., and Liu, W.-C.: Modeling of hydrodynamics and cohesive sediment processes in an estuarine system: Study case in Danshui river, Environ. Model. Assess., 15, 261-271, 2010.

Gurnell, A. M., van Oosterhout, M. P., de Vlieger, B., and Goodson, J. M.: Reach-scale interactions between aquatic plants and physical habitat: River Frome, Dorset, River Res. Appl., 22, 667-680, 2006.

Kleinen, T. and Petschel-Held, G.: Integrated assessment of changes in flooding probabilities due to climate change, Climatic Change, 81, 283-312, 2007.

Kourgialas, N. N. and Karatzas, G. P.: Flood management and a GIS modelling method to assess flood-hazard areas - a case study, Hydrol. Sci. J., 56, 212-225, 2011.

Kourgialas, N. N. and Karatzas, G. P.: A hydro-economic modelling framework for flood damage estimation and the role of riparian vegetation, Hydrol. Process., 27, 515-531, 2013.

Kourgialas, N. N., Karatzas, G. P., and Nikolaidis, N. P.: An integrated framework for the hydrologic simulation of a complex geomorphological river basin, J. Hydrol., 381, 308-321, 2010.

Leu, J. M., Chan, H. C., Jia, Y., He, Z., and Wang, S. S. Y.: Cutting management of riparian vegetation by using hydrodynamic model simulations, Adv. Water Resour., 31, 1299-1308, 2008.

Lilli, M.: Development of a methodology for the assessment of river bank erosion in the Koiliaris River, Master's thesis, Department of Environmental Engineering, Technical University of Crete, Greece, 2011.

Masterman, R. and Thorne, C. R.: Predicting influence of bank vegetation on channel capacity, J. Hydrol. Eng., 118, 1052-1058, 1992.
Nadal-Romero, E., Regues, D., and Latron, J.: Relationships among rainfall, runoff, and suspended sediment in a small catchment with badlands, Catena, 74, 127-136, 2008.

Neary, V. S., Wright, S. A., and Bereciartua, P.: Case study: Sediment transport in proposed geomorphic channel for Napa River, J. Hydraul. Eng., 127, 901-910, 2001.

Parsa, J., Etemad-Shahidi, A., Hosseiny, S., and Yeganeh-Bakhtiary, A.: Evaluation of computer and empirical models for prediction of salinity intrusion in the Bahmanshir estuary, J. Coast. Res., (Spec. issue 50), 658-662, 2007.

Patro, S., Chatterjee, C., Mohanty, S., Singh, R., and Raghuwanshi, N.: Flood inundation modeling using MIKE FLOOD and remote sensing data, J. Indian Soc. Remote Sens., 37, 107-118, 2009.

Plate, E.: Flood risk and flood management, J. Hydrol., 267, 2-11, 2002.

Pramanik, N., Panda, R., and Sen, D.: One dimensional hydrodynamic modeling of river flow using DEM extracted river crosssections, Water Resour. Manage., 24, 835-852, 2010.

Rodriguez-Blanco, M. L., Taboada-Castro, M. M., and TaboadaCastro, M. T.: Factors controlling hydro-sedimentary response during runoff events in a rural catchment in the humid Spanish zone, Catena, 82, 206-217, 2010.

Tabacchi, E., Lambs, L., Guilloy, H., Planty-Tabacchi, A. M., Muller, E., and Decamps, H.: Impacts of riparian vegetation on hydrological processes, Hydrol. Process., 14, 2959-2976, 2000.

Tuteja, N. K.: Koondrook-Perricoota Forest Flood Enhancement Project - Hydraulic Modelling, Dept. of Environment and Climate Change NSW, Sydney South, ISBN:9781741226720, 2008.

USACE1: US Army Corps of Engineers, HEC-River Analysis System, Hydraulic Reference Manual, Version 3.1, 2002.

van Alphen, J. and Passchier, R.: Atlas of Flood Maps, examples from 19 European countries, USA and Japan, Ministry of Transport, Public Works and Water Management, The Hague, Netherlands, available at: http://ec.europa.eu/environment/water/flood_ risk/flood_atlas/index.htm (last access: 12 March 2013), 2007.

Vereecken, H., Baetens, J., Viaene, P., Mostaert, F., and Meire, P.: Ecological management of aquatic plants: effects in lowland streams, Hydrobiologia, 570, 205-210, 2006.

WHO (World Health Organisation): Guidelines for Drinking Water Quality, Volume 2: Health criteria and other supporting information, Geneva, 1996. 